\title{
Finite element model updating of semi-composite bridge decks using operational acceleration measurements
}

\author{
Néstor R. Polanco ${ }^{\mathrm{a}}$, Geoffrey May ${ }^{\mathrm{b}}$, Eric M. Hernandez ${ }^{\mathrm{a}}$ \\ ${ }^{a}$ Dept. of Civil and Env. Engineering. University of Vermont. 103 Votey Hall, 33 Colchester Ave., \\ Burlington VT 05405, USA \\ ${ }^{b}$ OBEC Consulting Engineers
}

\begin{abstract}
Composite bridge decks provide higher flexural moment capacity and stiffness compared to their non-composite counterparts. In order to achieve composite behavior, differential slip between the steel member and the concrete slab must be restrained by means of shear connectors. In older bridge decks composite behavior is uncertain. Uncertainty arises, among other things, due to lack of knowledge regarding the type of shear connector used (if any), cumulative damage due to fatigue, and aging effects. In this paper the authors propose the use of sensitivity-based finite element model updating to determine the degree of composite behavior of operational bridge decks with uncertain shear connectors. The free parameters of the models are: rigidity per unit length of the beam-slab interface and the elastic modulus of the concrete slab. The features used in the model updating procedure are the identified modal frequencies from operational acceleration measurements. A sequential sensitivitybased weighted least-squares solution was implemented. The proposed methodology is verified in various simulated bridge deck structures and validated in an operational and partially instrumented bridge deck with uncertain composite action.

Keywords:

Model Updating, Bridge Decks, Composite Action, Finite Element Models
\end{abstract}

\section{Introduction}

Based on data from the National Bridge Inventory approximately $24 \%$ of all multi-span bridges in the United States are constructed using steel girders and a concrete slab (1). This percentage is higher in the Northeast where it reaches approximately $63 \%$. One important component in this type of deck construction is shear connectors. Shear connectors enable composite behavior by transferring horizontal shear stresses between the steel beam and the concrete slab. Composite decks possess a significantly larger flexural strength and stiffness with respect to non-composite ones (2). Shear connectors are typically constructed by welding vertical steel studs to the top face of the top flange in steel girders prior to pouring of the concrete slab. The design of shear connectors is governed by two criteria; static strength and fatigue. Shear connectors are first designed for fatigue loads due to moving 
vehicles and then checked for static ultimate strength. Girders are checked for static ultimate strength assuming full composite action, i.e. the number of shear connectors is enough to transfer the horizontal shear force at the interface that results when the steel girder has fully yielded and the concrete slab has simultaneously reached its maximum compressive capacity. AASHTO LRFD Specifications require that steel girder/concrete slab decks be designed as fully composite (8). If a beam does not have enough connectors to guarantee fully-composite behavior, then it is categorized as partially composite and its ultimate load capacity is typically governed by the failure of shear connectors.

Whenever the structural integrity of an existing bridge deck needs to be assessed; the presence and effectiveness of shear connectors becomes a central issue. In older bridges with unknown construction practices, lack of as-built drawings and(or) cumulative damage effects such as fatigue, the effectiveness of shear connectors is uncertain. The most widely used approach in the practice of structural assessment of bridge decks with uncertain composite action consists in assuming no interaction between the concrete deck and the steel beam. This practice typically results in a diagnosis that is not cost effective and inconsistent with the fact that over the years of service some of these decks have withstood traffic loading beyond the strength provided by the non-composite assumption. An overly conservative diagnosis regarding a bridge deck could result in an unnecessary decision to replace, retrofit, or to reduce the load rating of the deck. Development of technologies capable of assessing the effectiveness of shear connectors and the degree of composite action in uncertain bridge decks would prove useful for engineers and public transportation decision makers.

A reasonable approach to assess the effectiveness of composite action in a deck is to instrument it with sensors capable of measuring the strains in the vicinity of the steelconcrete interface. If the strain measurements in the steel and concrete near the interface are close, then one can infer that there is negligible relative slip between the two surfaces and composite behavior is verified (at least within the range of loading consistent with the measurements). As an alternative, one can measure the strain at various points along the depth of the steel girder and interpolate (or extrapolate) the location of the neutral axis. Using principles from structural mechanics, the level of composite action can be inferred from the estimated location of the neutral axis. This last approach is only valid if no net axial force is present in the deck. One drawback of strain-based approaches is that they require significant instrumentation and can only assess composite action at a local level, i.e. at the section where the strain is measured.

Recent examples of the strain measurement approach can be found in the literature. In (4) Breña et al. present results from monitoring an I-girder type highway overpass under a controlled live load test. A total of 60 strain measurements were used to estimate load distribution factors and these results were compared with the results from a finite element model (FEM). The researchers found that although the deck was designed as non-composite, the strain measurements across the cross section (assuming Bernoulli's hypothesis of linear strain distribution) were consistent with the condition of I-girders acting as composite with the reinforced concrete slab. In (5) Chakraborty and DeWolf developed and implemented a continuous strain monitoring system on a three-span composite I-girder overpass. The 
instrumentation consisted of 20 uniaxial strain gages. The study reported on data over a period of 5 months. Among other things, the study included the determination of the location of the height of the neutral axes of various structural members when large trucks travel across the bridge. One of the conclusions of this study was that the measured strain levels are typically significantly below those recommended by AASHTO. The authors stated that this is a byproduct of conservative simplifications typically used in conventional designs, such as not including redundancies, connection restraints, and the way in which loads are distributed to different parts of the structure. This conclusion is in agreement with a previous study (6).

Jauregui et al. (7) conducted a series of controlled field loading tests on a standard Igirder bridge built in the late $1950^{\prime} s$ and assigned for decommission. Measurements consisted of strains and vertical deformations at various points. Results of the investigation show that the deck behaved as if partially composite right up to the onset of yielding. Partial composite action occurred in spite of the lack of shear connectors between the girders' top flange and the concrete slab. This suggests that partially composite action of the girders can be attributed to friction due to the slab bearing down on the girder top flange and mechanical interlock at the girder-deck interface. Jauregui et al. argued that these two forms of shear restraint are dependable if not overcome and thus may be used to arrive at a better measure of the bending stiffness and resistance of the deck.

The main hypothesis of this paper is that global acceleration measurements induced by traffic can be used to estimate the stiffness provided by the presence of partial composite action in bridge decks. Specifically, free vibration response shortly after the vehicle leaves the deck. Laboratory experiments conducted by various researchers on isolated composite beams provide encouraging results which indicate that this approach might be scalable to operational bridge decks $(9 ; 10)$.

Morassi et al. (9), performed a theoretical and experimental laboratory investigation into the behavior of isolated, free-free steel beams-concrete slab composite beams. They found that if shear connectors are damaged, then their effect can be seen in the changes in vibration frequencies. It is expected that their general conclusions extrapolate to cases with different boundary conditions. Finally, Kwon et al. (10) performed a series of controlled laboratory experiments aimed at testing the effectiveness of post-installed shear connectors. After examination of their experimental results, it is possible to conclude that steel girders with concrete slabs that do not possess explicit shear transfer mechanisms in the form of shear connectors; exhibit a flexural stiffness that lies between the fully-composite and noncomposite assumptions. It can also be concluded that the difference between the overall stiffness of a composite beam with shear connectors versus an identical one without shear connectors can be observed even within the range of linear stresses.

The use of acceleration measurements presents several advantages with respect to localized strain monitoring: (i) the overall integrated behavior of the deck can be assessed as opposed to a more local examination provided by the strains measurements (ii) a smaller number of sensors could be used to perform the assessment, making instrumental monitoring of these type of structures more affordable. We propose the use of a sensitivity-based 
weighted finite element model updating to determine the degree of composite behavior in operational bridge decks with unknown/uncertain installation of shear connectors. The free parameters of the model are the rigidity per unit length of the beam-slab interface and the elastic modulus of the concrete slab. The features used in the model updating procedure are the identified modal frequencies and their corresponding mode shapes extracted from global acceleration measurements. A sequential weighted least-squares solution was implemented with a diagonal weighting matrix on which each element is inversely proportional to the variance of the identified modal features.

From the perspective of model updating, the fundamental challenges addressed in this paper are to determine if: (a) the concrete modulus of elasticity and the interface stiffness are independently identifiable from a subset of modal frequencies and (b) the sensitivity of frequencies to changes in the free parameters is large enough to overcome the "noise" in the identified modal parameters. The identification noise is important because bridges are subjected to variations in environmental conditions that affect boundary conditions and stiffness properties of the material, which in turn get reflected as changes in modal properties.

The proposed approach is verified in the context of numerical simulations and validated in an operational and partially instrumented bridge deck located in the state of Vermont, USA. The bridge was built in 1963 and it supports two lanes of traffic. The deck consists of a concrete slab supported on three inner longitudinal stringers and two exterior girders. The interior stringers are supported on transverse floor beams simply connected to the two main longitudinal girders. The bridge spans a total of $170.08 \mathrm{~m}$ (558ft). A portion of the bridge deck was instrumented with a total of 10 vertical accelerometers distributed along the length of stringers.

The paper begins with a section describing the sensitivity-based model updating procedure to be employed. The procedure uses eigenvalue sensitivity in order to set up the linear set of equations. It also includes a weighting matrix to account for the relative variance in the identification of the modal features. The paper continues with a section describing the various models and assumptions to be used through the rest of the paper. This is followed by sections describing two-dimensional and three-dimensional numerical simulations aimed at verifying the proposed methodology. A section describing the application in the context of an operational bridge deck concludes the computational portion of the paper. The paper ends with a section highlighting the main findings, limitations and potential future work.

\section{Sensitivity-based model updating}

Finite element model updating can be defined as a series of computational steps, in which a preselected set of model parameters within a particular model class are modified to minimize a function of the difference between response measurements of the system and model predictions $(20 ; 23)$. More formally this can be stated as: Given a model class $\mathcal{M}(\theta)$ with response feature vector $y_{\mathcal{M}} \in \mathbb{R}^{m}$ and corresponding system response feature vector $y_{\mathcal{S}} \in \mathbb{R}^{m}$, modify an $f$-dimensional subset $\theta_{f} \subset \theta$ such that a local minimum of the function $J=g(\Delta y)$ is attained, where $\Delta y=y_{\mathcal{S}}-y_{\mathcal{M}}$. The subset $\theta_{f}$ is typically referred to as the free parameter 
space. In general, the response features and model parameters exhibit a non-linear relationship. The relation between the response features and perturbations in the free model parameters $\Delta \theta_{f}$ can be written as

$$
y_{\mathcal{M}}\left(\theta_{f}+\Delta \theta_{f}\right)-y_{\mathcal{M}}\left(\theta_{f}\right)=\mathbf{S} \Delta \theta_{f}+\text { H.O.T. }
$$

where H.O.T represents higher order terms in $\Delta \theta_{f}$, the matrix $\mathbf{S} \in \mathbb{R}^{m \times f}$ and each component of it is defined as

$$
S_{i j}=\frac{\partial y_{\mathcal{M}, i}}{\partial \theta_{f, j}}
$$

The objective function $J$ is typically selected as a quadratic form

$$
J=\epsilon^{T} \mathbf{W} \epsilon
$$

where

$$
\epsilon=\Delta y-\mathbf{S} \Delta \hat{\theta}_{f}
$$

$\mathbf{W} \in \mathbb{R}^{m \times m}$ is a weighting matrix and $\Delta \hat{\theta}_{f}$ is the estimated change in the free parameters. If $m \geq f$ then the solution that minimizes $J$ is obtained by

$$
\Delta \hat{\theta}_{f}=\alpha\left(\mathbf{S}^{T} \mathbf{W S}\right)^{-1} \mathbf{S}^{T} \mathbf{W}\{\Delta y\}=\mathbf{F}\{\Delta y\}
$$

where $0<\alpha \leq 1$ is a scalar. The purpose of $\alpha$ is to reduce the estimated change in the model parameters to avoid unrealistic variations (overshooting) byproduct of the linearization in eq.1. The covariance of the estimates in each step of the updating is given by

$$
\operatorname{COV}\left[\Delta \hat{\theta}_{f}\right]=\mathbf{F} C O V[\{\Delta y\}] \mathbf{F}^{T}
$$

In this study the measurement features will consist of a subset of modal frequencies and(or) their corresponding mode shape amplitudes at sparse locations. Analytical closedform expressions of the sensitivity of eigenvalues and mode shapes in undamped multi-degree of freedom systems can be found in the literature $(21 ; 19)$. The sensitivity of eigenvalues to parameters that define the mass and(or) stiffness is given by

$$
\frac{\partial \lambda_{j}}{\partial \theta_{k}}=\phi_{j}^{T}\left[-\lambda_{j} \frac{\partial \mathbf{M}}{\partial \theta_{k}}+\frac{\partial \mathbf{K}}{\partial \theta_{k}}\right] \phi_{j}
$$

This expression is very convenient because it only involves the mode shape corresponding to the frequency of interest. In cases where the computation of closed-form sensitivities becomes computationally expensive or prohibitive, one can always resort to a less elegant computation given by 


$$
S_{i j} \approx \frac{\Delta y_{\mathcal{M}, i}}{\Delta \theta_{f, j}}
$$

This requires careful selection of $\Delta \theta_{f, j}$ and the solution of multiple eigenvalue problems in order to compute the changes in eigenvalues and eigenvectors.

\section{Model Formulation}

The mathematical theory describing the behavior of composite beams with weak shear connectors subjected to unidirectional bending on a symmetry plane has been studied in depth by various researchers (11), (12), (13) and (14); just to mention a few. More recently, Dall'Asta (16) developed a more complete theoretical formulation for three-dimensional cases. The author included out-of-plane bending and torsion based on Kirchhoff bending theory and Vlasov torsion theory. Ranzi et al. (17) performed a two-dimensional comparative study using four different formulations to analyze partially composite two-layer beams subject to symmetric bending, namely; the exact analytical solution, direct stiffness method, the finite element method and finite differences. The authors concluded that the direct stiffness method, formulated using basis functions from the exact solution, provides the best accuracy followed by the finite element method and the finite differences. This paper focuses on complex three-dimensional structures and does not assume prior knowledge of the basis functions from the exact solution, therefore a finite element model (FEM) formulation is preferred.

All finite element models (FEM) to be considered in this paper are linear, elastic with lumped mass and classical damping. The set of parameters $\theta$ consist of all the material properties necessary to formulate the stiffness, mass and damping matrices. The set of free parameters $\theta_{f}$ will be the elastic modulus of the reinforced concrete slab and the stiffness of the connecting elements representing the rigidity per linear unit of length of the interface between the steel girder and the concrete slab. The stiffness of the connecting elements will provide an indication of the overall degree of composite action between steel and concrete. In both cases the parameters represent homogenized averaged properties.

As mentioned previously the two fundamental problems to address are: (i) identifiability of parameters, i.e. Is it possible to separately identify the elastic modulus of concrete and the stiffness of the interface? (ii) Can these parameters be identified in the presence of noise or bias in the identified modal features? To investigate these two aspects, various scenarios and models with increasing complexity will be examined.

We begin with the simplified model of one of the stringers by considering it as a simply supported 2-dimensional continuous beam. The model has analogous sections and dimensions to the stringers (W18x60) and tributary area of the concrete slab. This model consists of two parallel longitudinal rows of frame-type elements for concrete slab (top) and the steel stringer (bottom); as shown in Fig.1a. The longitudinal elements are interconnected at intermediate nodes by massless perpendicular vertical elements that represent the stiffness of the interface that enables the composite behavior, Fig.1b. The model was implemented 
using a code developed by the third author in MATLAB environment Figure 1a shows the dimensions and general details of the specific model considered. The mass of the model is lumped at the nodes and the stiffness matrix is for horizontal and vertical degrees of freedom (rotations where condensed out).

We also study a 3-dimensional model analogous to the portion of the bridge deck that is instrumented as indicated in Fig.10. The model explicitly includes the main girders, floor beams, girders, bracings and slab. The model has 83,026 DOF, 932 frame members that represent the steel elements (girder, stringers, floor beams, bracings) and shear connectors, and 13,120 shell areas to model the concrete slab. The model was formulated using the software SAP2000 and it is shown in Fig. 2a, 2b and 2c.

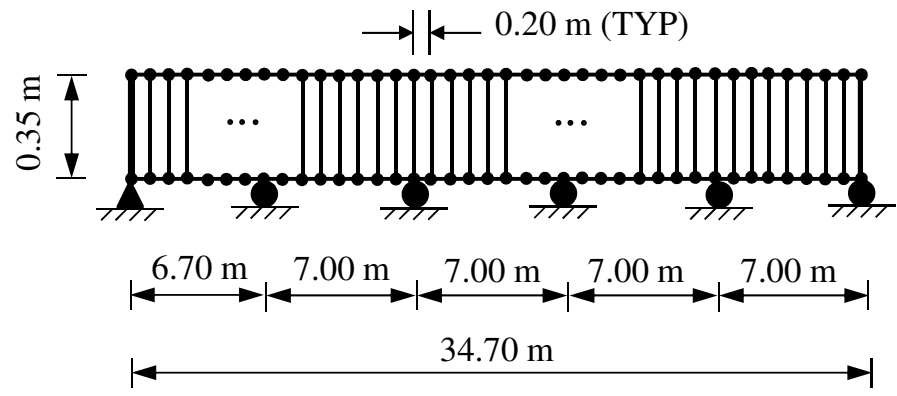

(a) Longitudinal section of two dimensional FEM of composite beam

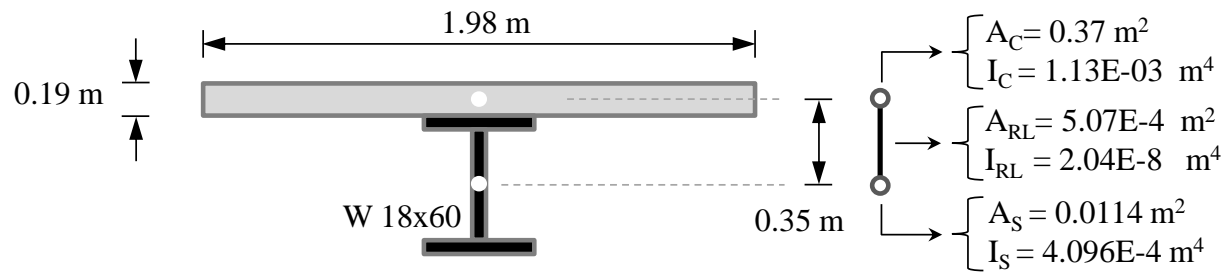

(b) Transverse section of two dimensional FEM of composite beam

Figure 1: Two dimensional FEM 


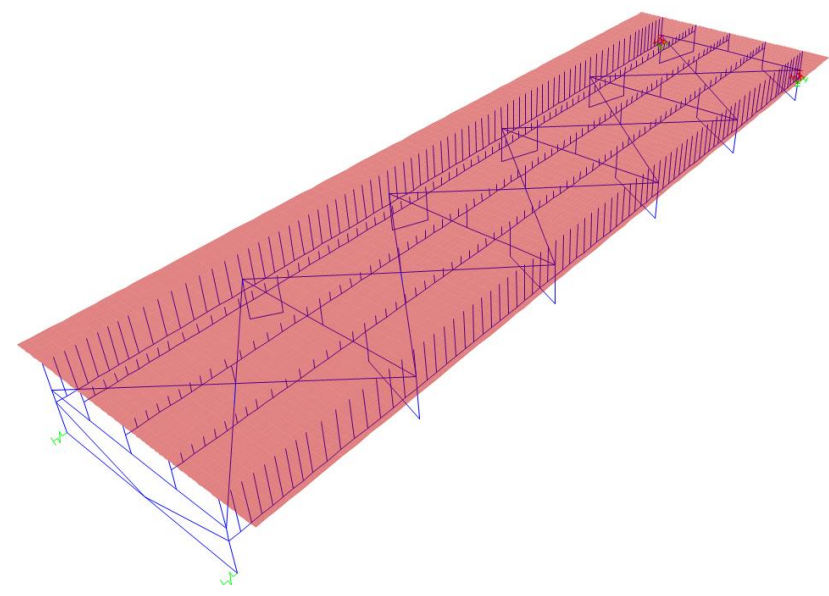

(a) Three dimensional FEM of bridge deck

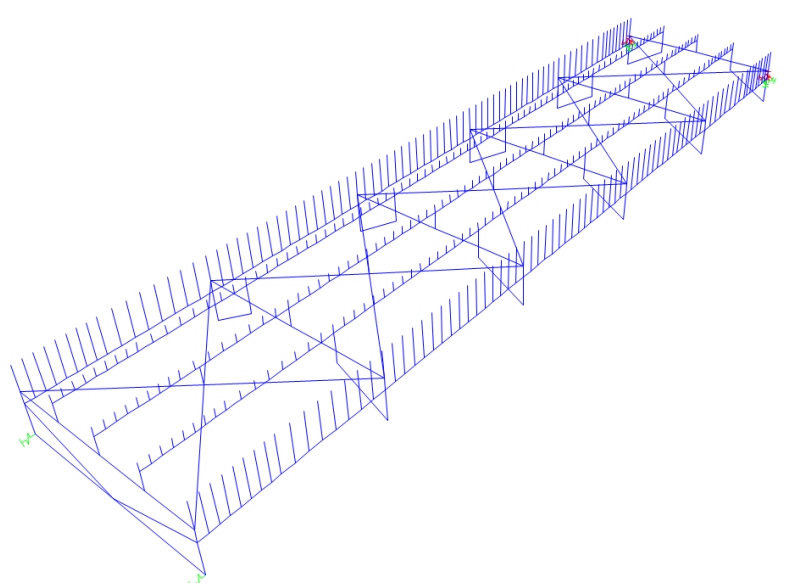

(b) Three dimensional FEM of bridge deck (no slab)

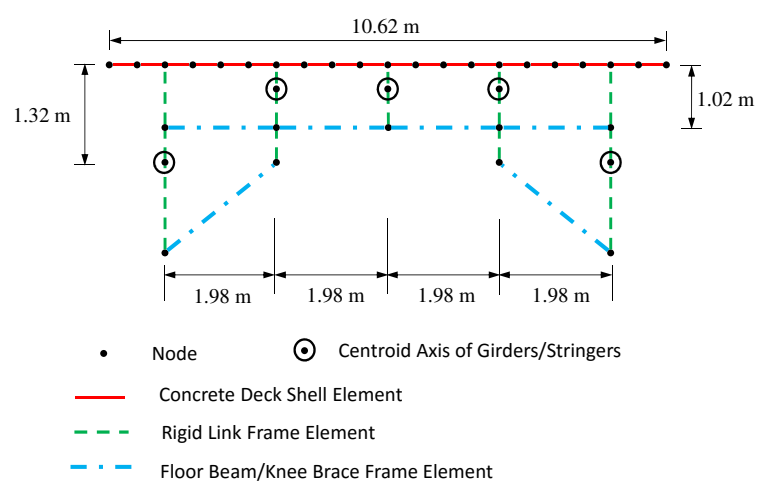

(c) Cross section of three dimensional FEM

Figure 2: Three dimensional FEM of bridge deck (see Fig. 10 for additional dimensions)

\section{Two Dimensional Model - Simulated Cases}

This section describes the simulation results corresponding to the application of sensitivitybased model updating to the 2-D semi-composite beam shown in Fig.1a. The main interest is to determine if the two free parameters $\theta_{1}=$ elastic modulus of concrete and $\theta_{2}=$ shear connector stiffness per linear meter are distinguishable based on the first five flexural modal frequencies of the deck.

Various cases where considered:

1. CASE 1: Identify a simultaneous increase of $20 \%$ in the rigidity per unit length of the vertical connectors and in the elastic modulus of concrete.

2. CASE 2: Identify a $20 \%$ decrease in the rigidity per unit length of the vertical connectors and an increase of $20 \%$ in the elastic modulus of concrete. 
3. CASE 3: Identify an increase of $100 \%$ in the rigidity per unit length of the vertical connectors while the elastic modulus of concrete remains unchanged. This was induced by reducing the separation of vertical connectors in half while keeping the stiffness of the individual connectors the same. This case involves the presence of model error since the model does not match the system used to generate the "identified" modal features.

Table 1: System and initial frequencies (prior to updating) for Cases 1, 2 and 3 in the 2D Model

\begin{tabular}{|c|c|c|c|c|}
\hline Frequency (\#) & SYSTEM (Hz) & CASE 1 (Hz) & CASE 2 $\mathbf{~ H z ) ~}$ & CASE 3 (Hz) \\
\hline 1 & 16.24 & 16.80 & 16.17 & 17.20 \\
\hline 2 & 17.40 & 18.042 & 17.30 & 18.63 \\
\hline 3 & 20.28 & 21.13 & 20.21 & 21.85 \\
\hline 4 & 22.86 & 24.13 & 22.84 & 24.92 \\
\hline 5 & 25.79 & 27.05 & 25.58 & 28.39 \\
\hline
\end{tabular}

The first two cases are intended to investigate the capability of the methodology to distinguish separate changes in the free parameters. For both cases the separation between the vertical connectors was selected as $s_{m}=0.20 \mathrm{~m}$. Case 3 examines the effect of model error. Here the separation of the connectors is inconsistent with the model and it is necessary to verify if the correct stiffness per unit length can still be estimated. For this case the system had a separation of vertical connectors $s_{\lambda}=0.10 \mathrm{~m}$ and the model $s_{m}=0.20 \mathrm{~m}$. For all cases, the sensitivity approach was implemented using only the discrepancies in the first six eigenvalues. In all cases the initial values of the free model parameters are $3,630 \mathrm{kN} / \mathrm{m} / \mathrm{m}$ for the rigidity per unit meter of the rigid connectors and $28 \mathrm{GPa}$ for the elastic modulus of concrete.

Figures 3, 4 and 5 show the evolution of the free model parameters as the number of iterations increases for cases 1,2 and 3 respectively. It can be seen that in all cases, despite some initial overshooting, the selected free parameters converge to the target values. This suggests that the parameters are independently identifiable from changes in modal frequencies. 

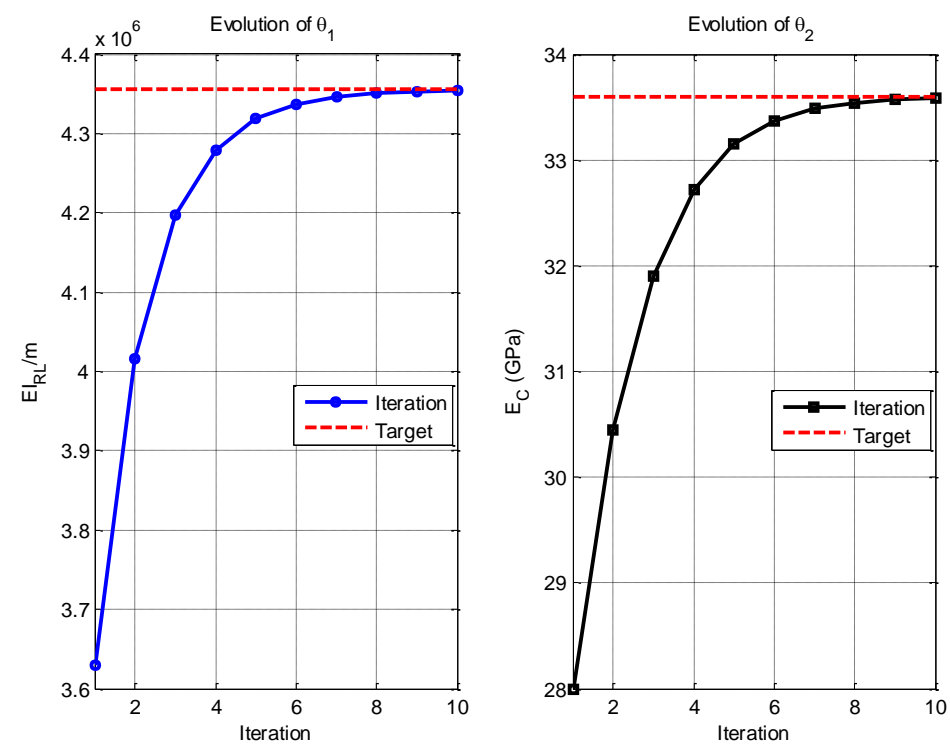

Figure 3: Evolution of model parameters a)Rigidity per linear meter and b) elastic modulus of concrete for Case 1 of 2D FEM
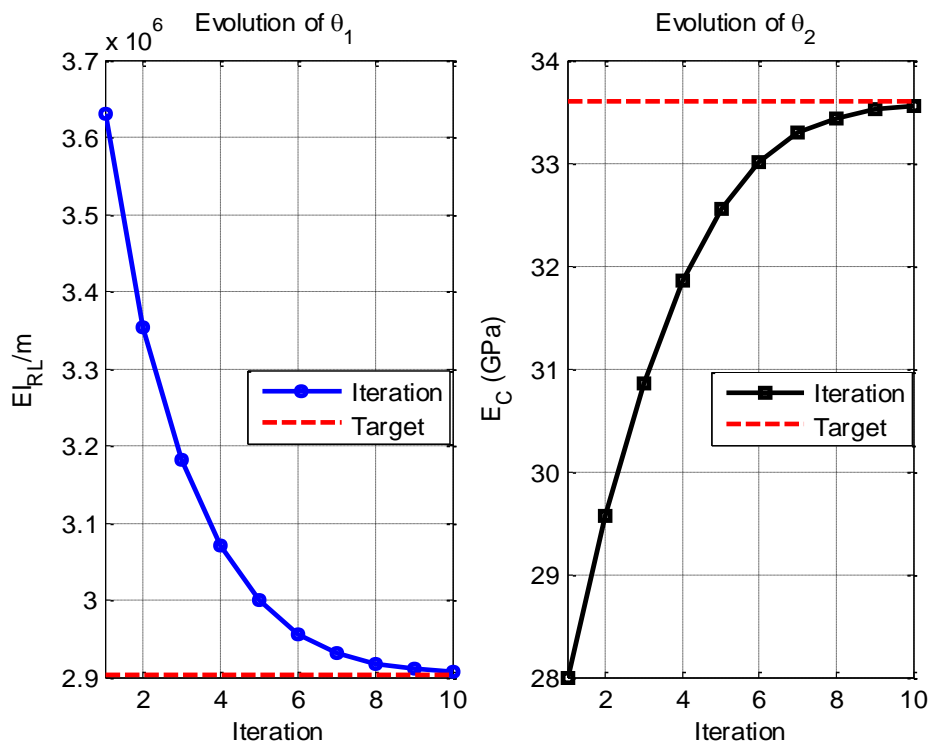

Figure 4: Evolution of model parameters a)Rigidity per linear meter and b) elastic modulus of concrete for Case 2 of $2 \mathrm{D}$ FEM 

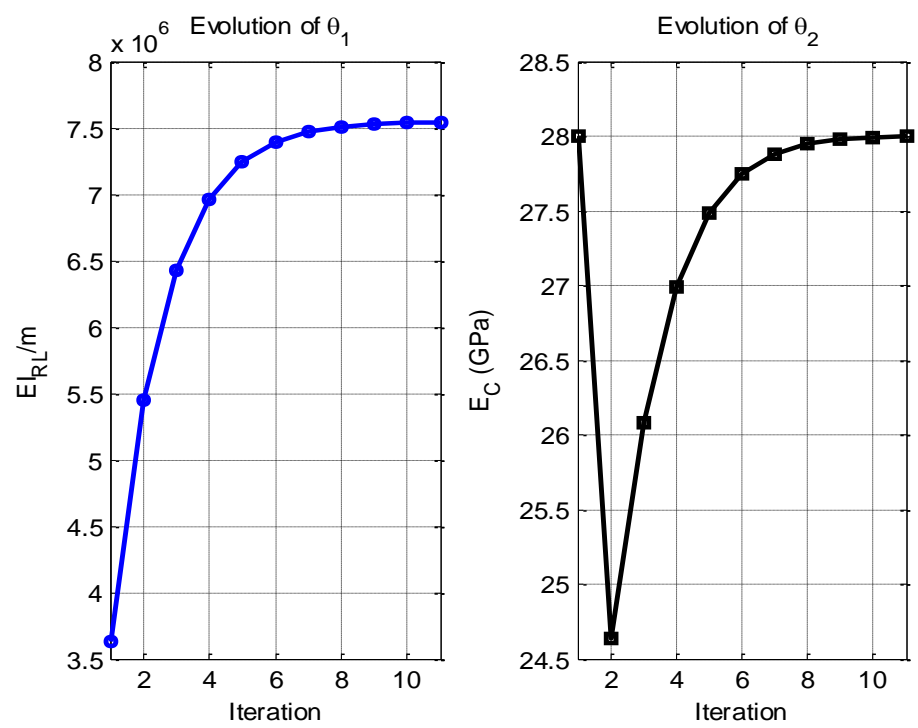

Figure 5: Evolution of model parameters a)Rigidity per linear meter and b) elastic modulus of concrete for Case 3 of 2D FEM

\section{Three Dimensional Model - Simulated Cases}

Following encouraging results from updating a 2D FEM of an isolated stringer, verification of the sensitivity approach using a 3D FEM is investigated. This model simulates the instrumented portion of the bridge deck shown in Fig.10. Cases 1 and 2 from the previous section are investigated, namely

1. CASE 1: Identify a simultaneous increase of $20 \%$ in the rigidity per unit length of the vertical connectors and in the elastic modulus of concrete.

2. CASE 2: Identify a $20 \%$ decrease in the rigidity per unit length of the vertical connectors and an increase of $20 \%$ in the elastic modulus of concrete.

Table 2 shows the five modal frequencies used to perform the model updating. The table also shows the initial values of the frequencies prior to updating corresponding to each case. The sensitivity matrix was approximated using eq.8. The value of $\Delta \theta_{f}$ to compute the changes in modal parameters was selected as $0.01 \theta_{f}$. The sensitivity matrix is shown in Fig.6. As expected the eigenvalues are more sensitive to changes in the concrete modulus, however the sensitivity due to changes in the stiffness of the shear links is not negligible. 


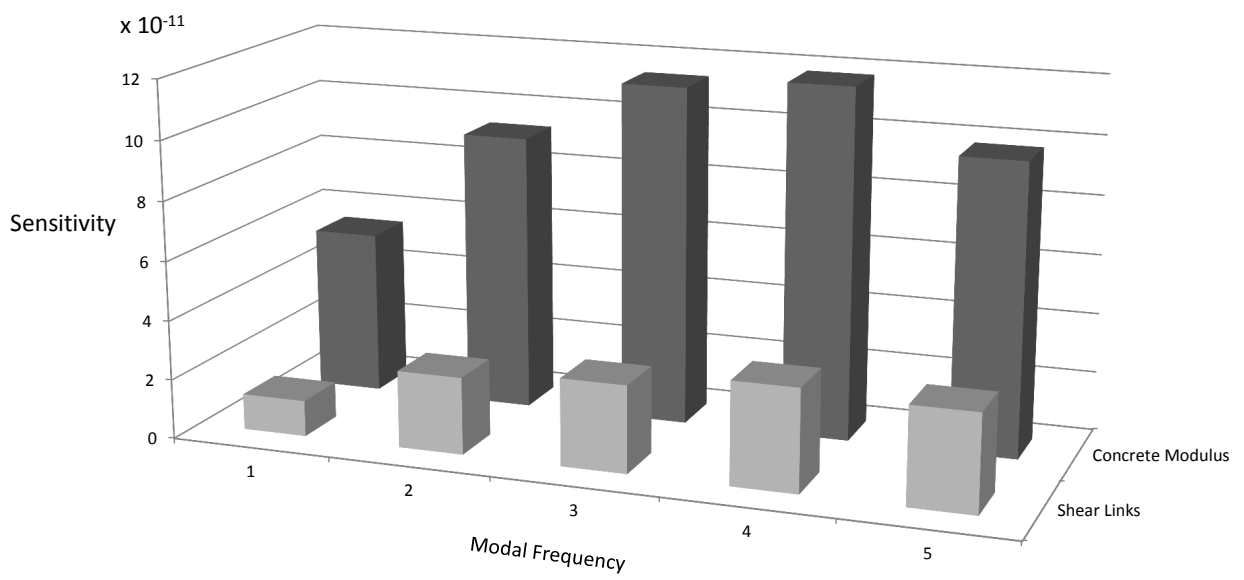

Figure 6: Sensitivity matrix of first five eigenvalues to concrete elastic modulus and stiffness of shear links.

Table 2: System and initial model frequencies (prior to updating) for Cases 1 and 2 in the 3D Model

\begin{tabular}{|c|c|c|c|}
\hline Frequency $(\#)$ & SYSTEM $\mathbf{( H z )}$ & CASE 1 $\mathbf{( H z )}$ & CASE 2 $\mathbf{( H z )}$ \\
\hline 1 & 14.05 & 14.35 & 14.30 \\
\hline 2 & 17.16 & 17.69 & 17.58 \\
\hline 3 & 18.15 & 18.80 & 18.67 \\
\hline 4 & 18.83 & 19.51 & 19.37 \\
\hline 5 & 22.19 & 19.51 & 19.37 \\
\hline
\end{tabular}

Figs. 7 and 8 show the results for Cases 1 and 2 respectively. In similar fashion to the 2D FEM, the modal features and the model parameters converge to the target values. 

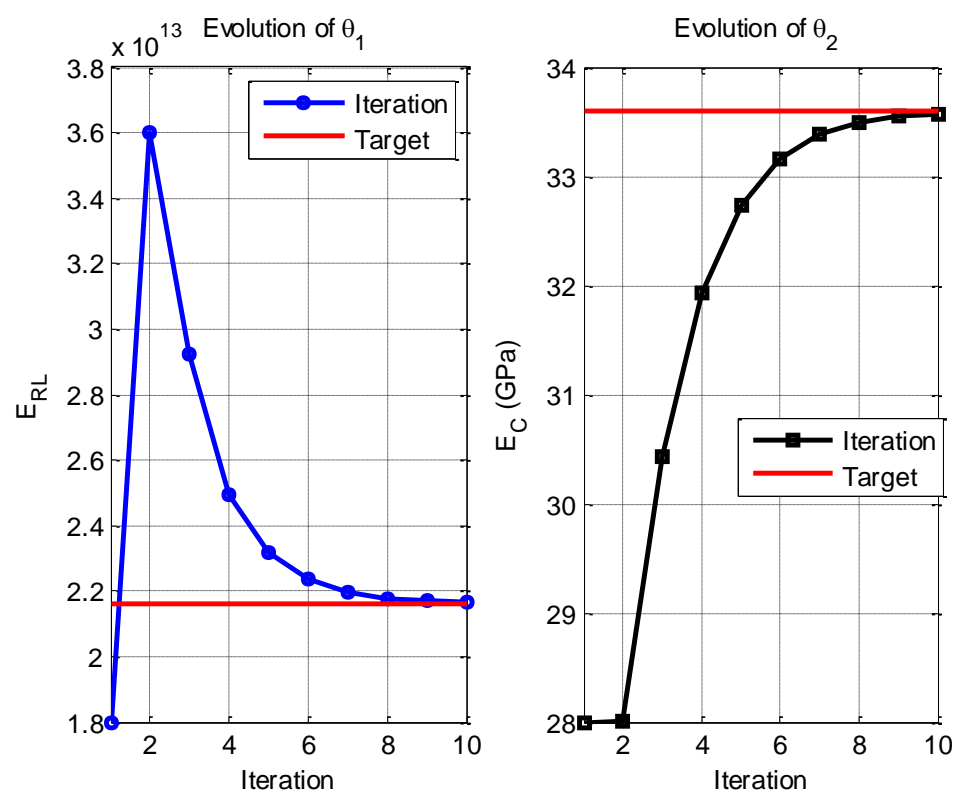

Figure 7: Evolution of model parameters a)Rigidity per linear meter and b) elastic modulus of concrete for Case 1 of 3D FEM
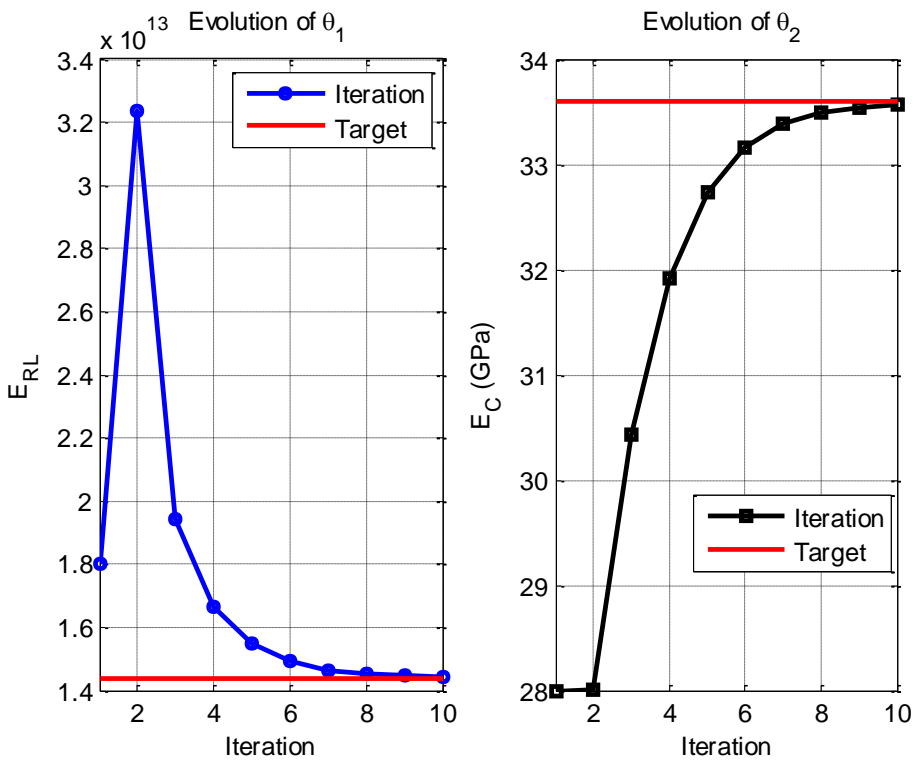

Figure 8: Evolution of model parameters a)Rigidity per linear meter and b) elastic modulus of concrete for Case 2 of 3D FEM

\section{Validation Using Data from an Operational Instrumented Bridge}

Having established that it is possible to distinguish between stiffness changes in shear connectors and the concrete slab based on changes in modal frequencies, it is appropriate to 
proceed and apply the proposed method in the context of an instrumented and operational bridge deck. Bridges 58N \& S are twin bridges along interstate 89 in Vermont, USA. For this study, only the two-lane north-bound bridge was instrumented. The bridge was designed in 1961 and built in 1963. As can be seen from Fig.10 the deck is supported on two longitudinal built-up I-girders, which rest upon two intermediate reinforced concrete piers and at the ends on reinforced concrete abutments.

A typical cross section of the deck is depicted in Fig.10. The reinforced concrete slab (190mm thick) is supported at the ends on the main longitudinal girders (with variable depth between $2.44 \mathrm{~m}$ (at the midspan) and $4.27 \mathrm{~m}$ (at the supports) and on continuous intermediate stringers (W18x60) parallel to the main girders. The stringers are supported on a transverse floor beam (W36 x 170) which itself is simply supported on the main girders. The transverse floor beams are spaced at $7.01 \mathrm{~m}$ on-center.

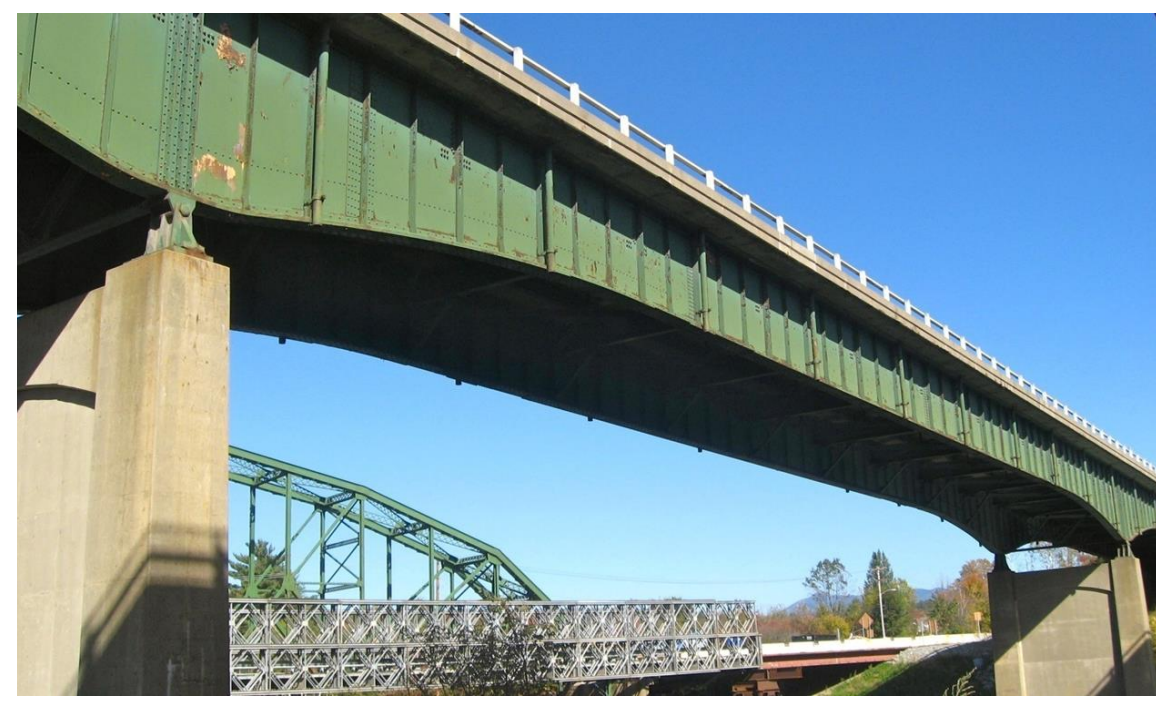

Figure 9: Photograph of bridge 58N located in Vermont, USA. 


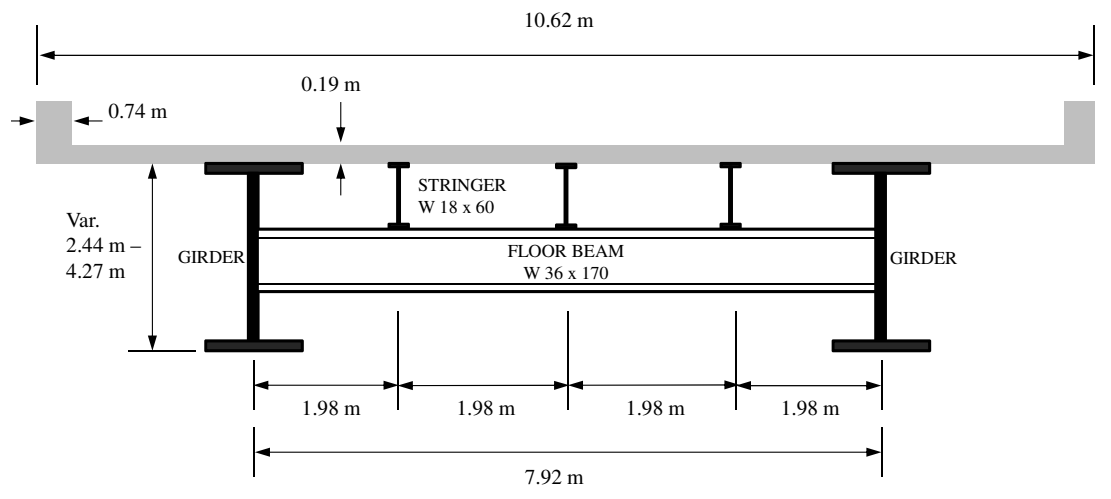

(a) Cross section of bridge deck

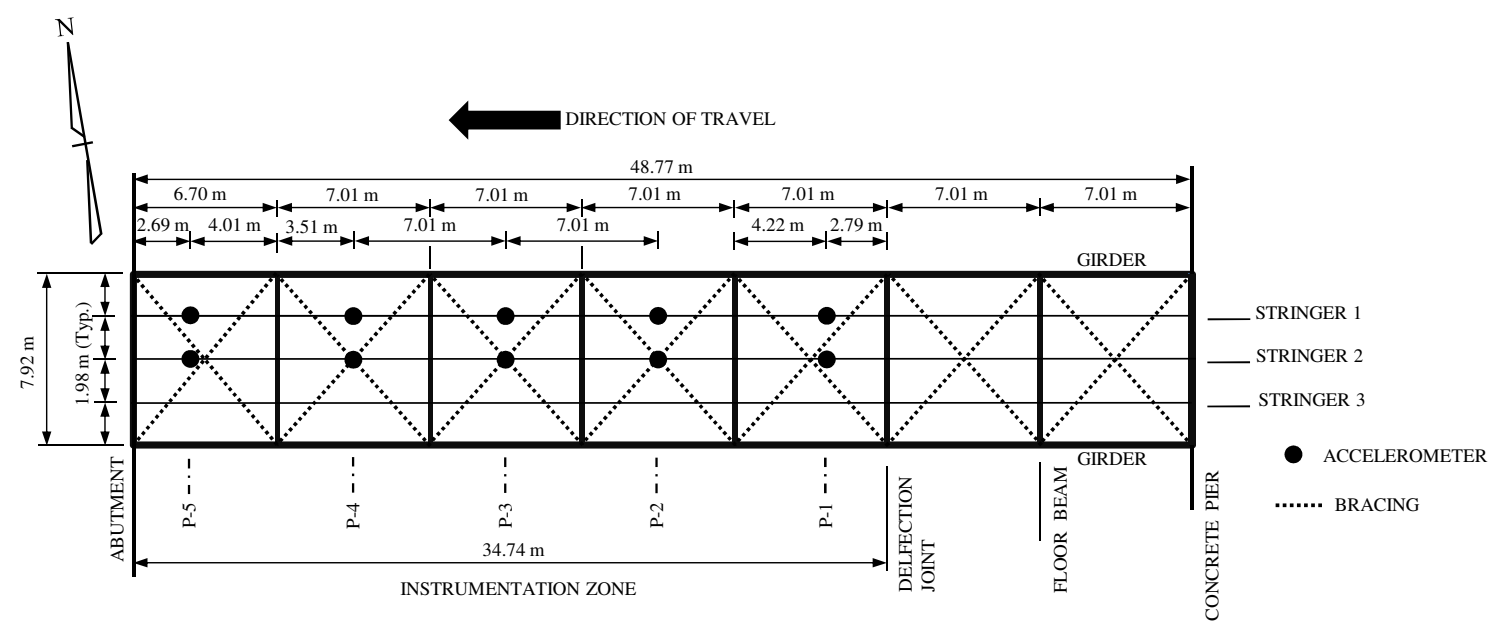

(b) Instrumentation layout

Figure 10: (a)Cross section of bridge deck and (b) instrumentation layout (See Fig.2 for FEM model)

\subsection{Modeling}

As can be seen from Fig.2a, the model is a substructure of the bridge. The boundary conditions of the model are as follows: (i) rigid vertical supports at the abutment, (ii) longitudinal spring supports at the abutment (representing the horizontal rigidity of the support at the abutment) and (iii) springs and masses at the opposite end, these represent the stiffness and mass necessary to achieve the static displacement, the fundamental vertical and torsional modal frequencies of the complete bridge deck. The free parameters of the model are the stiffness per unit length of the shear connectors between the slab and the stringer, and the elastic modulus of the concrete deck. 


\subsection{Instrumentation}

Instrumentation on the bridge deck consists of 10 accelerometers (PCB Model 393A03) as shown in Fig.10. The deck was also instrumented with dynamic strain sensors, but those measurements will not be used for the purposes of this paper, for more information regarding the strain measurements see (18). The location of the accelerometers was selected to capture the maximum expected structural response of the stringers while at the same time minimizing the required number of sensors (due to budgetary constraints). It is worth noting that the main interest in the instrumentation is to capture the structural behavior of the stringers, however due to the interconnected nature of the structural system, some aspects of the global structural response will also be captured. To perform the data acquisition the LMS SCADAS MOBILE SCM05 with a uniform sample rate of $200 \mathrm{~Hz}$ was used. The data collection presented in this study begins April 12, 2012 and concludes November 20, 2013, with a hiatus between August 27, 2012 and August 28, 2013. Therefore, the data spans between April and November of a nominal year. Measurements consist of 1-hour long records recorded sporadically during this interval. To reduce the effect of input uncertainty (weight, speed or lane of travel of the vehicles) only free vibration measurements were used in this analysis. A total of 184 free vibration intervals were selected from the measured data. The criteria for selection was that the length of the record be longer than 10 seconds after the vehicle left the bridge while no other vehicle entered the bridge during that time. The measured temperature during the selected intervals ranged from $15^{\circ} \mathrm{F}$ to $87^{\circ} \mathrm{F}$. Typical acceleration measurements during the passing of a heavy truck are shown in Fig.11.
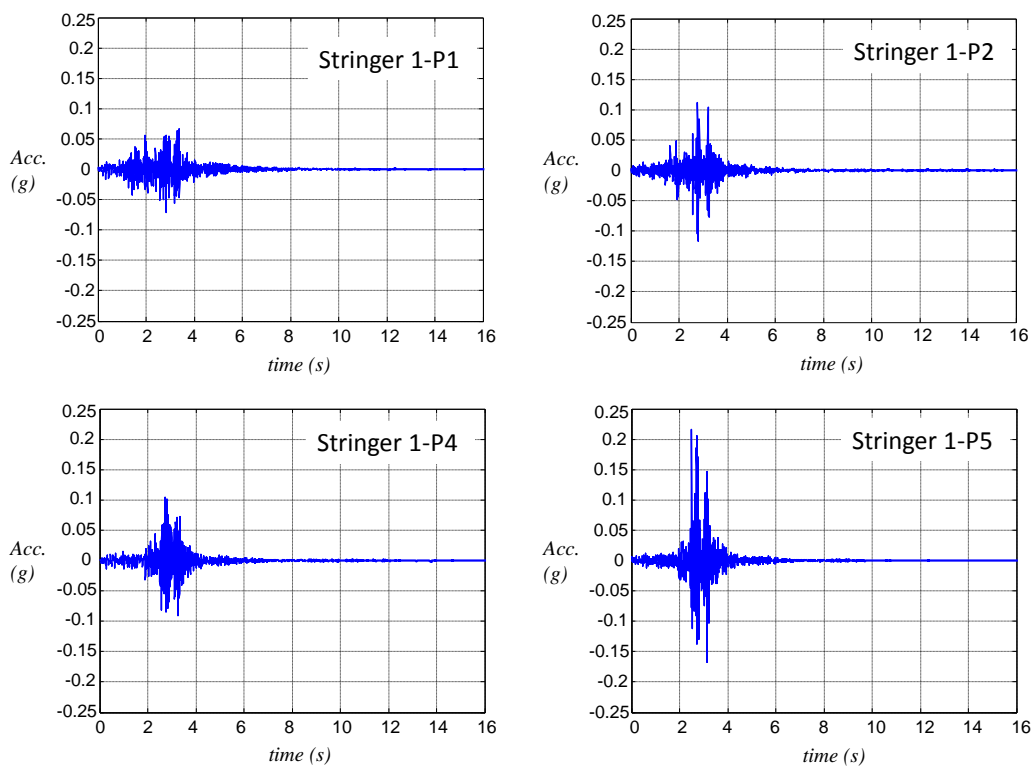

Figure 11: Acceleration measurements at various positions along Stringer-1 during the passing of a truck on the travel lane (see Fig.10b for sensor location coordinates) 


\subsection{System Identification}

Knowledge of the characteristics of the traffic experienced by the bridge, vehicle speed, weight and traveling lane, is rarely available. As a way to reduce uncertainty related to the traffic induced excitation, free vibration responses are used for the system identification. This is only possible because of the low average daily traffic on this bridge, for bridges with constant traffic more advanced methods are necessary. The acceleration intervals were processed using the Eigensystem Realization Algorithm (ERA) (22). The ERA identifies a linear model of the form

$$
\begin{gathered}
x(k+1)=\mathbf{A} x(k)+\mathbf{B} u(k) \\
y(k)=\mathbf{C} x(k)+\mathbf{D} u(k)
\end{gathered}
$$

where $x(k)$ is the internal state at time $t=k \Delta t, u(k)$ is the input, $y(k)$ is the output. The A matrix, also known in control literature as the state transition matrix, and it carries information about the system eigenvalues. The mathematical formulation to extract the system frequencies from the eigenvalues of $\mathbf{A}$ can be found in (22). A summary of the identified modal frequencies from the selected data set is shown on Fig. 12.
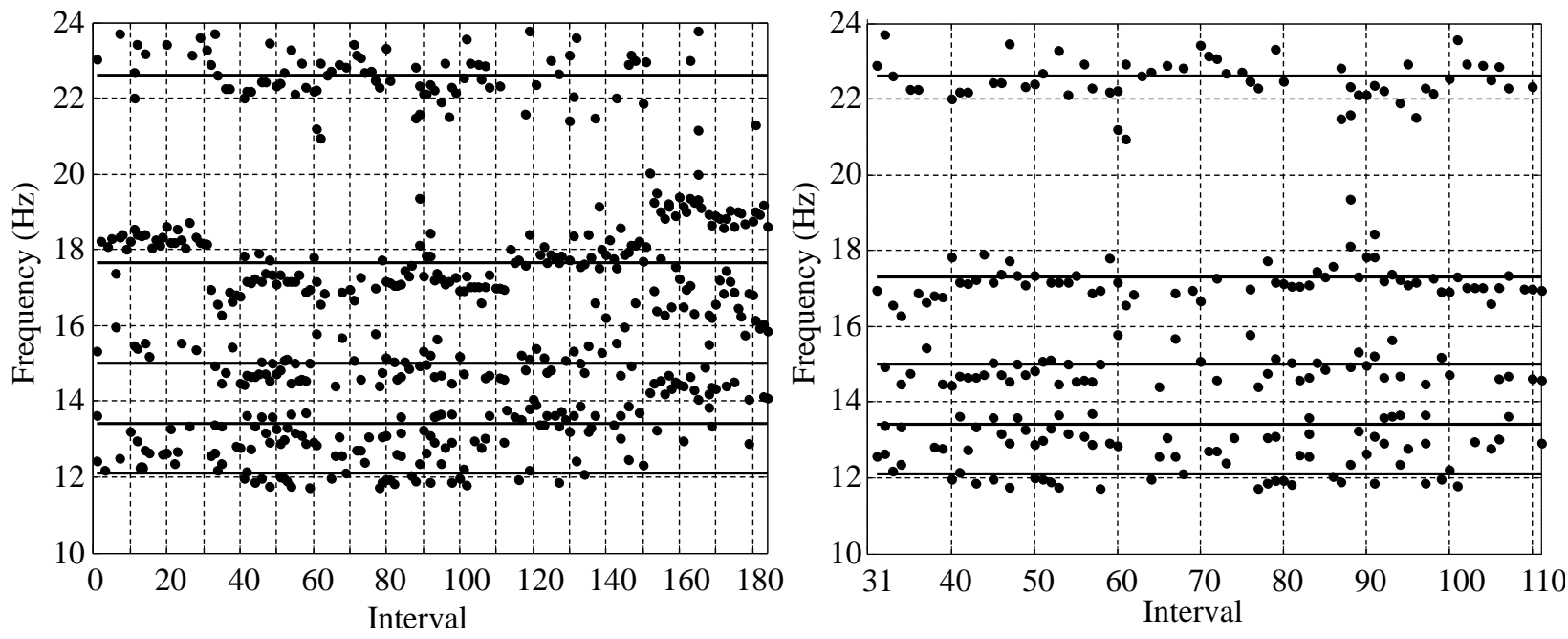

(a) Identified frequencies between April and November (b) Identified frequencies between July and October

Figure 12: Identified frequencies from global acceleration measurements. Mean values indicated by dotted lines

From Fig.12 it can be observed that during colder months the natural frequencies experience an increase with respect to the warmer summer months. This change occurs in all mode shapes and it appears to be reversible, so it can not be attributed to a structural damage. We attribute it to temperature and humidity variations which affect the mechanical 
properties of the deck and boundary conditions.

\subsection{Model Updating Results}

This section presents a summary of the results from the implementation of the finite element model updating procedure described in Section 2. Two scenarios are compared: (i) using all identified frequencies across the complete time interval of measurements and (ii) using only the subset of the data corresponding to the summer months.

In both cases the variance of the identified frequencies is computed and a diagonal weighting matrix is computed. The $i^{\text {th }}$ diagonal element of the weighting matrix is the inverse of the variance of the $i^{\text {th }}$ identified frequency. For convenience purposes, the weighting matrix is scaled in such manner that the diagonal of the weighting matrix adds to unity. This is an arbitrary choice since the weighting matrix can be multiplied by any scalar without changing the result of the weighted least-squares solution. For each case, two different procedures were implemented. In the first one, the model updating algorithm was unconstrained while in the second one, the algorithm was constrained to operate within reasonable limits for the variables,specially the concrete modulus of elasticity. The selected lower and upper bound for the concrete elastic modulus were $21.37 \mathrm{GPa}$ and $27.59 \mathrm{GPa}$ respectively, this corresponds to a lower bound of a compressive strength of concrete of $20.68 \mathrm{MPa}(3 \mathrm{ksi})$ and an upper bound of $34.47 \mathrm{MPa}(5 \mathrm{ksi})$. The expression used to link concrete strength and elastic modulus was $E_{c}=4700 \sqrt{f^{\prime} c}(M P a)(8)$.

The model updating results for the scenario where all the data was used is presented in Tables 3 and 4 . The model updating results for the scenario where only a subset of the data was used is presented in Tables 5 and 6.

Table 3: Model Parameters - Using complete data set

\begin{tabular}{|c|c|c|c|}
\hline Parameter & Initial & Unconst. & Const. \\
\hline$E_{c}(G P a)$ & 28 & 10.08 & 21.5 \\
\hline$k_{L}(M N / m / m)$ & 516.6 & $2,857.7$ & 4.2 \\
\hline
\end{tabular}

Table 4: Comparison of frequencies Bridge $58 \mathrm{~N}$ - Using complete data set

\begin{tabular}{|c|c|c|c|c|c|c|}
\hline Freq. (\#) & ID $\mathbf{~ H z )}$ & $\sigma^{\mathbf{2}}$ & $\mathbf{W}$ & Initial (Hz) & Unconst. (Hz) & Const. (Hz) \\
\hline 1 & 12.04 & 0.65 & 0.09 & 14.04 & 12.64 & 12.94 \\
\hline 2 & 13.37 & 0.14 & 0.43 & 17.16 & 14.90 & 14.40 \\
\hline 3 & 15.02 & 0.30 & 0.28 & 18.15 & 15.58 & 14.52 \\
\hline 4 & 17.80 & 0.69 & 0.08 & 18.83 & 16.24 & 14.84 \\
\hline 5 & 22.57 & 0.42 & 0.11 & 22.19 & 19.58 & 19.72 \\
\hline
\end{tabular}

Fig.13 shows a semi-log plot depicting the variation of the main vertical frequencies of the deck as a function of the stiffness per unit length of the shear connectors. The plots 
Table 5: Model Parameters - Using reduced data set

\begin{tabular}{|c|c|c|c|}
\hline Parameter & Initial & Unconst. & Const. \\
\hline$E_{c}(\mathrm{GPa})$ & 28 & 15.3 & 21.5 \\
\hline$k_{L}(\mathrm{MN} / \mathrm{m} / \mathrm{m})$ & 516.6 & $26,889.8$ & 5.9 \\
\hline
\end{tabular}

Table 6: Comparison of frequencies Bridge $58 \mathrm{~N}$ - Using reduced data set

\begin{tabular}{|c|c|c|c|c|c|c|}
\hline Freq. $(\#)$ & ID $\mathbf{( H z})$ & $\sigma^{\mathbf{2}}$ & $\mathbf{W}$ & Initial $\mathbf{( H z )}$ & Unconst. $(\mathbf{H z})$ & Const. $(\mathbf{H z})$ \\
\hline 1 & 12.15 & 0.11 & 0.26 & 14.04 & 13.33 & 12.96 \\
\hline 2 & 13.20 & 0.10 & 0.29 & 17.16 & 16.08 & 14.49 \\
\hline 3 & 14.86 & 0.16 & 0.22 & 18.15 & 16.86 & 14.60 \\
\hline 4 & 17.21 & 0.21 & 0.13 & 18.83 & 17.56 & 14.94 \\
\hline 5 & 22.49 & 0.30 & 0.10 & 22.19 & 21.08 & 19.76 \\
\hline
\end{tabular}

shows the frequencies corresponding to the initial model and to the updated model (using a subset of the data shown in Fig.12(b)).

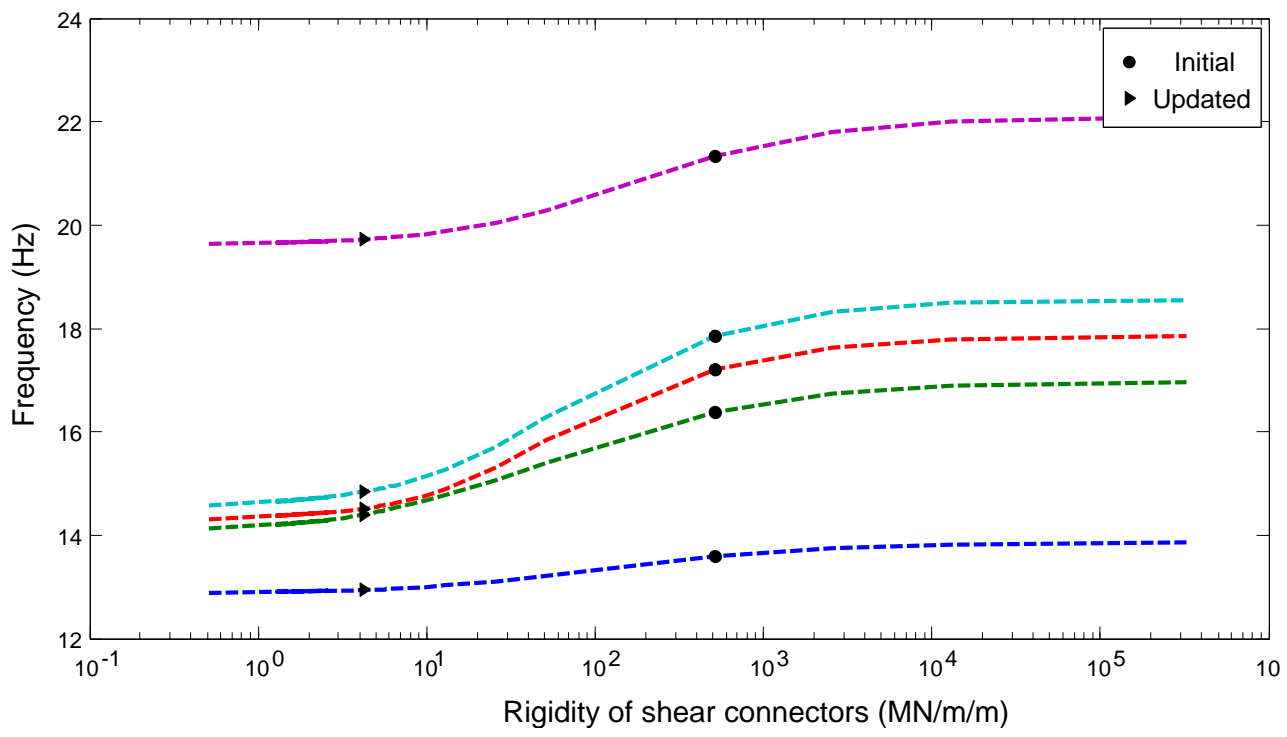

Figure 13: Frequencies of deck as a function of the effective stiffness of the shear connectors. Shown are the values of the initial stiffness (solid circle) and the updated value (solid triangle)

Fig.14 shows the mode shapes (in the concrete slab) corresponding to the constrained and unconstrained model updating. For both cases the reduced data set was used. As can be seen, significant differences exist between the unconstrained and constrained model updating results. 


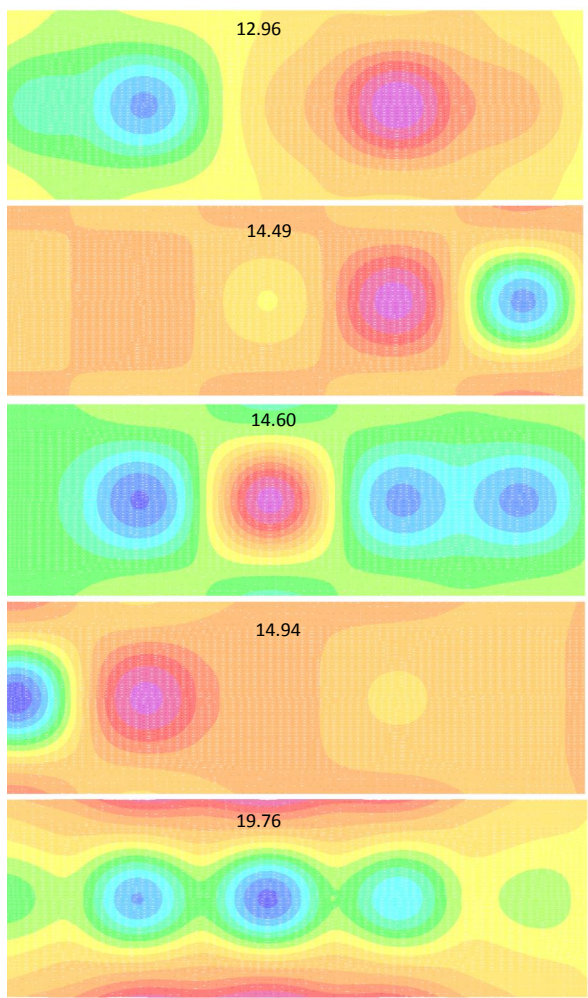

(a)

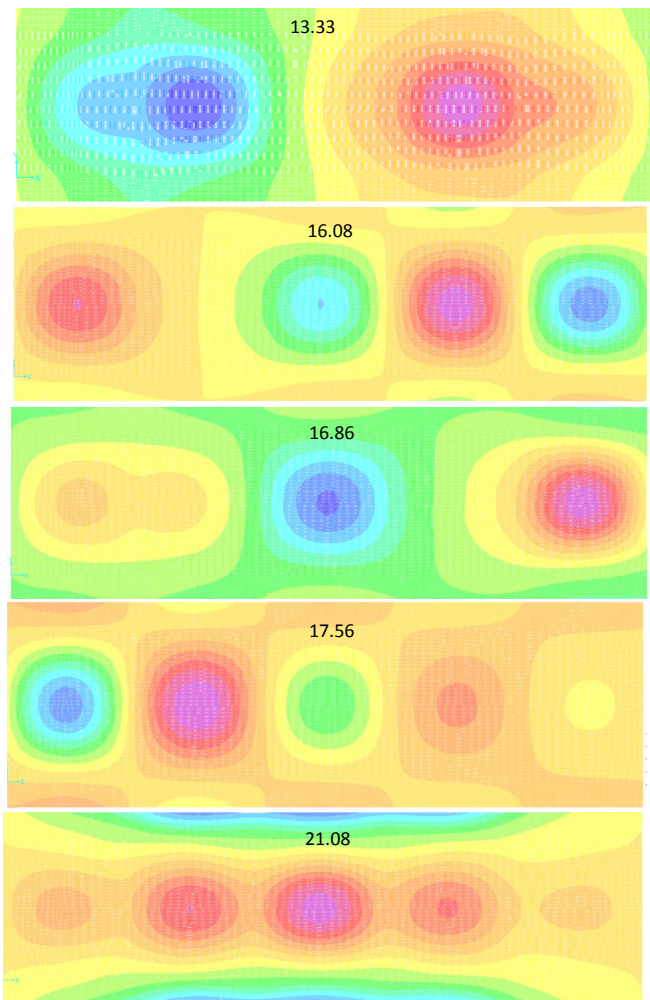

(b)

Figure 14: Mode shapes on the concrete slab corresponding to the updated model. On the left is the result of the constrained model updating and on the right the results of the unconstrained. 


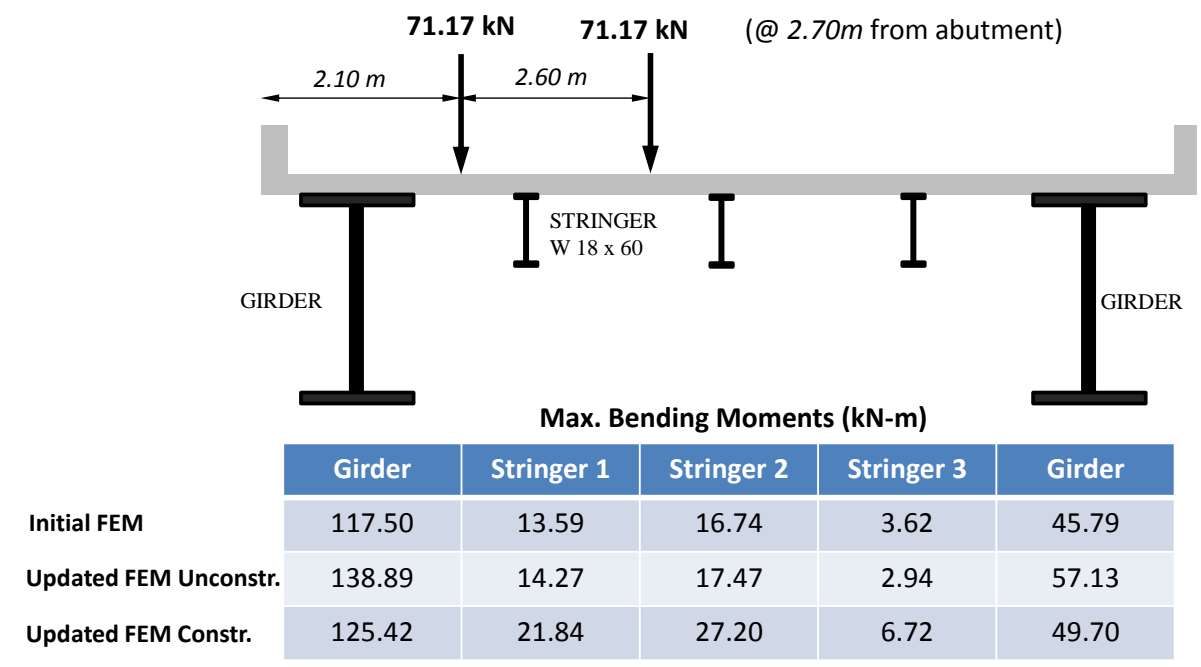

Figure 15: Comparison of maximum bending moments in various elements of the bridge deck

Fig. 15 presents a comparison between the maximum bending moments in the stringers and outer girders as a function of the updated composite behavior of the deck. The loading is a pair point loads as indicated in the figure. These loads represent the last axle of a three axle truck. The position of the loads corresponds to the most critical, in the sense that it creates the largest bending moment. The constrained updated model presents significant differences with respect to the unconstrained model, specially in the stringer bending moments. The unconstrained model presents a very high level of composite action and a very low slab stiffness, this translates into a higher level of loads going into the girders with lower loads going into the stringers. In the constrained model, the slab is much stiffer in comparison with the unconstrained case and thus this means a better and more even transverse distribution of forces.

\subsection{Validation of Updated Finite Element Model}

In this section a validation of the updated finite element model (constrained FEM) is presented. The data was derived from a test conducted on the bridge deck. The bridge was subjected to a passing truck driven on the travel lane with known axle weight and spacing (measured off site). The truck had three axles weighting $30 k N, 100 k N$ and $100 k N$ from front to back. The spacing of the axles was $3.00 \mathrm{~m}$ and $6.00 \mathrm{~m}$ respectively. The truck was driven at a constant speed of $60 \mathrm{mph}$ on the travel lane. During the passing of the truck, accelerations were measured at all locations indicated in Fig.10. Similarly, the updated finite element model was subjected to a set of simulated moving point loads with the same magnitude, relative spacing and speed as the actual truck. For this simulation a modal damping ratio of 0.035 for every mode was used. This is consistent with identified damping from vibration measurements on the bridge deck. 


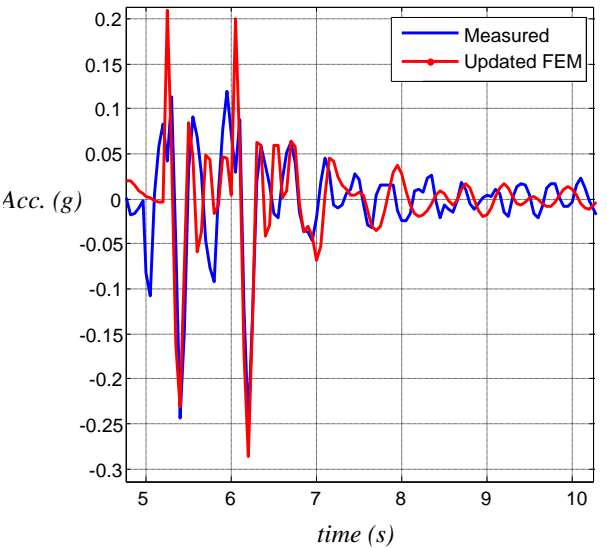

Fig.16 and 17 show a comparison between the measured acceleration, the original model and the updated model predictions. The improvement in prediction capability as a product of the model updating can be easily observed.

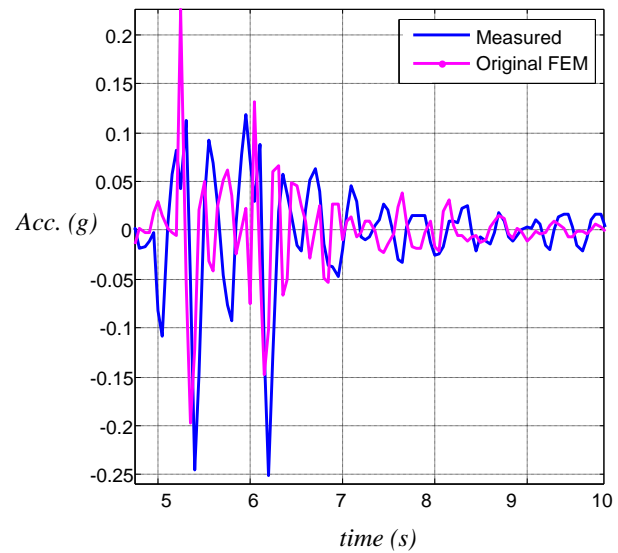

Figure 16: Comparison of acceleration response (updated model vs. orignal model) at stringer 1 (position P-5) when a test vehicle crosses the bridge in the travel lane at $60 \mathrm{mph}$.
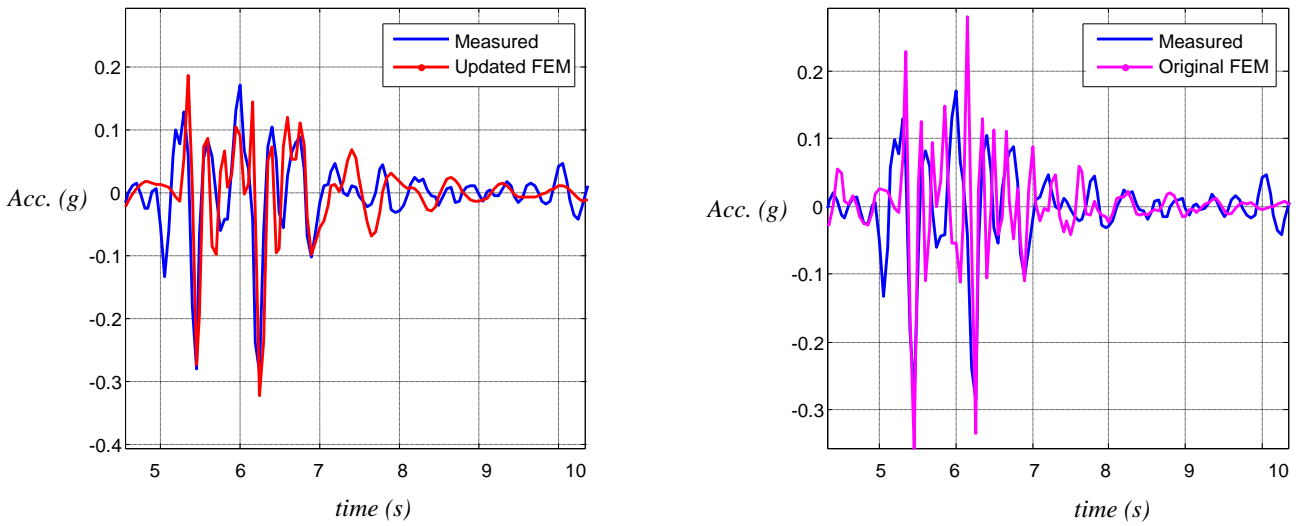

Figure 17: Comparison of acceleration response (updated model vs. orignal model) at stringer 2 (position $\mathrm{P}-5$ ) when a test vehicle crosses the bridge in the travel lane at $60 \mathrm{mph}$.

\section{Conclusions}

In this paper the authors propose the use of a weighted sensitivity-based finite element model updating to determine the degree of composite behavior in operational bridge decks with unknown/uncertain installation of shear connectors. The free parameters of the model are 
the rigidity per unit length of the beam-slab interface and the elastic modulus of the concrete slab. The type of measurements used are vertical accelerations at various points in the span. The number of measurements required by the proposed methodology are significantly less than the ones required if the more traditional strain sensing is used, with the drawback that the estimated quantities represent the behavior of the deck in an average sense and not section-by-section.

The proposed methodology was verified by means of numerical simulations in two models that varied in size and complexity. The first model was a 2D FEM of an isolated stringer in a bridge deck. The second model was a 3D FEM of a deck substructure. For each model, various levels of composite action were considered. In all cases, the modal features were selected as a subset of the system eigenvalues and the procedure accurately updates the model parameters related to composite action. The method was implemented in an operational and partially instrumented deck located in Vermont, USA. The variability of the identified data features was accounted in the model updating procedure by means of a weighting matrix (inversely proportional to the variance of the identified frequencies). As expected, identified modal frequencies varied significantly from summer to winter and thus two separate analysis were conducted, one with the complete data set and the other with a reduced data set which included only the summer months.

As an illustrative exercise, two model updating strategies were compared, constrained versus unconstrained. In the unconstrained case, the free parameters did not have limits or bounds, while, as the name suggests, in the constrained cases the elastic modulus of concrete was constrained to a lower bound. It was found that these two model updating solutions result in different structural behaviors of the bridge (static and dynamic). The unconstrained solution results in a very low (and physically unreasonable) value of the concrete modulus in the slab and a very high value for connection stiffness; the constrained solution provides more reasonable results and was thus adopted. The updated FEM, using the constrained approach, was further validated using measured accelerations induced by a moving test truck with known axle weight and spacing. It was found that the updated model provided an improved match between predictions and measurements in comparison with the original model. This exercise highlights the need for sound physical understanding of the variables when performing a model updating.

A limitation of the proposed model updating approach (which is independent of the type of sensing used) is that only stiffness of the deck can be assessed and not much can be learned regarding its ultimate static capacity. This is because various types of shear connectors can provide similar stiffness but display very different post-yielding behavior. Nevertheless, if the interest is the formulation of a finite element model that can be used as a base-line model for stress analysis (say for fatigue life estimation and(or) load distribution factors) then the proposed model updating approach would prove useful. 


\section{Acknowledgments}

The research presented in this paper was partially funded by the Vermont Agency of Transportation and by the National Science Foundation Grant ECC-1342190. Their support is gratefully acknowledged. The contents of this paper only reflect the views of the authors. The contents do not necessarily reflect the official view or policies of the Vermont Agency of Transportation.

\section{Bibliography}

[1] National Bridge Inventory. U.S. department of Transportation. Federal Highway Admisnistration. http://www.fhwa.dot.gov/bridge/nbi.cfm

[2] Salmon, C. and Johnson, J. Steel Structures, 4th edition. Prentice Hall. Upper Saddle River, N.J.(1996)

[3] Chen W-F, Duan, L. Bridge Engineering Handbook. CRC Press, N.Y.(1999)

[4] Breña, S., Jeffrey, A., and Civjan, S. (2013). âĂİEvaluation of a Noncomposite Steel Girder Bridge through Live-Load Field Testing.â̆̊̇ J. Bridge Eng., 18(7), 690âĂŞ699.

[5] Chakraborty, S. and DeWolf, J. (2006) âĂIJDevelopment and implementation of a continuous strain monitoring system on a multi-girder composite steel bridgeâĂİ ASCE Journal of Bridge Engineering 11(6): 753-762

[6] Kim, S. and Nowak, A.S. (1997) âĂIJLoad distribution and impact factors for I-girders bridgesâĂİ ASCE Journal of Bridge Engineering 2(3): 97-104.

[7] Jauregui, D. V., Yura J. A., Frank, K. H., and Wood, S. L. (2002) âĂIJField evaluation of decommissioned non-composite steel girder bridgeâĂİ ASCE Journal of Bridge Engineering 7(1): 39-49

[8] American Association of State Highway and Transportation Officials (AASHTO) (2010) LRFD bridge design specifications, Washington, D.C.

[9] Morassi, A. and Rocchetto, L.(2003) "A damage analysis of steel-concrete composite beams via dynamic methods: Part I, experimental results" Journal of Vibration and Control (9):507-527.

[10] Kwon, G., Engelhardt, M.D. and Klingner, R.E., "Strengthening bridges by developing composite action in existing non-composite bridge girders" Structural Engineering International, International Association for Bridge and Structural Engineering, 19(4): 432-437 (2009)

[11] Newmark, N.M., Siess, C.P. and Viest, I.M., Test and analysis of composite beams with incomplete interaction. Proceedings of the Society of Experimental Stress Analysis 9(1): 75-92 (1951) 
[12] Girhammar, U.A. and Pan, D., Dynamic analysis of composite members with interlayer slip, International Journal of Solid and Structures 30(6):797-823 (1993)

[13] Oehlers, D.J. and Sved, G. Composite beams with limited slip capacity shear connectors, ASCE Journal of Structural Engineering 121(6):932-938 (1995)

[14] Nguyen, N.T., Oehlers, D.J. and Bradford, M.A., A rational model for the degree of interaction in composite beams with flexible shear connectors, Mechanics of Structures and Machines 26(2):175-194 (1998)

[15] Oehlers, D.J., Nguyen, N.T., Ahmed, M. and Bradford, M.A. Partial Interaction in Composite Steel and Concrete Beams with Full Shear Connection, Journal of Constructional Steel Research 41(2/3):235-248 (1997)

[16] Dall'Asta, A., Composite beams with weak shear connection, International Journal of Solids and Structures, 38, 5605-5624 (2001)

[17] Ranzi, G., Gara, F., Leoni, G. and Bradford, M. A., Computers and Structures, 84, 930-941 (2006)

[18] Hernandez, E. M. and May, G., Vibration Monitoring and Load Distribution Characterization of I-89 Bridge 58N, Proceedings of the XXXI International Modal Analysis Conference (IMAC) Orange County, CA (2013)

[19] Mottershead, J. E. Link, M. and Friswell M.I., The sensitivity method in finite element model updating: A tutorial, Mechanical Systems and Signal Processing (2010).

[20] Friswell M.I. and Mottershead, J. E. Finite Element Model Updating in Structural Dynamics. Kluwer Academic Publishers, Dordrecht, 1995.

[21] Fox, R. L. and Kapoor, M. P., Rates of change in eigenvalues and eigenvectors. American Institute of Aeronautics and Astronautics Journal, 6(12): 2426-2429 (1968)

[22] Juang, L., Applied System Identification Prentice Hall. Upper Saddle River, NJ. (1999).

[23] Zárate, B. A. and Caicedo, J. M., Finite element model updating: Multiple alternatives, Engineering Structures, 30, 3724-3730, (2008) 